Gut, 1972, 13, 973-975

\title{
A comparison of results of excision and bypass for ileal Crohn's disease
}

\author{
J. ALEXANDER-WILliAMS, J. F. FIELDING, AND W. T. COOKE
}

From the General Hospital, Birmingham

SUMMARY One hundred and ten patients presented with Crohn's disease confined to the terminal ileum, and indications for their surgical treatment are reviewed. Treatment was either by ileotransverse side-to-side bypass (21 patients) or primary excision and end-to-end ileo-colic anastomosis (89 patients). In a long follow up (mean 13.8 years) the date and indications for the second major operative intervention are recorded. The cumulative risk of recurrence recorded each year after the primary operation shows that after bypass compared with excision there is approximately twice the risk of requiring a further major operation. After bypass the indication for the second operation is usually a local complication of the still active disease and after excision it is usually a juxtaanastomotic recurrence with stenosis.

For many years one of the most controversial questions relating to the surgical treatment of Crohn's disease was whether the treatment of choice should be a bypass procedure or a resection. Between 1925 and 1935 Berg in New York was practising excision by right hemicolectomy with a side-to-side ileo-transverse anastomosis (Garlock, 1967). Because this operation was associated with a high mortality the surgeons at Mount Sinai Hospital, New York, changed from excision to bypass with exclusion. In 1951 they published their results comparing the treatment by excision with that following bypass. There was a very much lower mortality and lower recurrence rate following the bypass operation and so was born the vogue for bypass operation which has persisted for many years (Garlock, Crohn, Klein, and Yarnis, 1951). Since then there has been a gradual swing away from bypass towards excision as the standard operation for ileal Crohn's disease (Colcock and Braasch, 1968).

In the light of the different opinions we have reviewed our experience in Birmingham.

\section{Material and Methods}

In the present series 110 patients with ileal Crohn's disease have had, as their initial operation, either excision or bypass. They have been followed from four to 38 years (mean 13.8 years). Twenty-one were

Received for publication 16 October 1972. treated initially by bypass and 89 initially by resection. The bypass operations tended to be performed in the 1940s and early 1950 s and the excision operations have been performed since then with a shorter follow-up period.

It is of course difficult to be certain that the clinical presentation of the two groups was identical as the indications for surgical treatment and the detail of note keeping have altered during the four decades of this study. The two groups of patients were similar in that all were patients with chronic Crohn's disease and the duration of disease from presentation of first symptoms to first operation was not significantly different.

Each group of patients has been studied to determine whether the type of initial operation influenced the subsequent life history of the patient. This has been measured by recording the number of subsequent operations needed to treat recurrent Crohn's disease and by noting the interval between the first excisional or bypass operation and the next operation for Crohn's disease, also by determining the reasons for the second definitive operation. In all patients in this series the diagnosis of Crohn's disease has been confirmed histologically, either at the time of primary excision or, in patients treated initially by bypass, at subsequent resection.

\section{Results}

CRUDE RECURRENCE RATE (FIGURE 1)

In the group initially treated by bypass all but one 


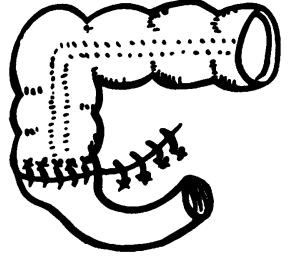

A

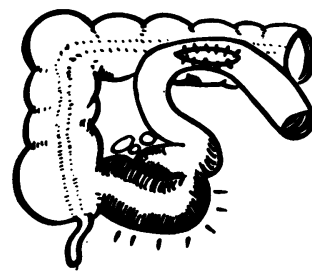

B
Fig. 1 The diagrams depict the two types of operative treatment used to treat Crohn's disease of the terminal ileum. There were no operative deaths and the crude recurrence rate is as follows: A 89 patients, excision; recurrence (43) $48 \%$; B 21 patients, bypass; recurrence (20) $95 \%$.

required a further definitive operation (either further bypass, excision, or ileostomy) for Crohn's disease. This one patient died 15 years after the bypass operation with severe recurrence of Crohn's disease. He was not then under our care, and, in our present state of knowledge, should have been treated by re-operation. There is, therefore, a reoperation rate of $95 \%$ and a recurrence rate of $100 \%$.

After primary excision 46 patients $(51.5 \%)$ required a second operation during the time under review. However, this comparison between the two operations is not valid as the patients had been followed longer after the bypass operation and recurrence in Crohn's disease is known to be related to the length of follow up (Garlock et al, 1951; Van Patter, Bargen, Dockerty, Feldman, Mayo, and Waugh, 1954; Brooke, 1959; Lennard-Jones and Stalder, 1967; Fielding, Cooke, and Williams, 1972).

\section{CUMULATIVE RISK OF RECURRENCE}

A comparison that has more meaning than the crude recurrence rate is one that takes into account the length of follow up. A cumulative risk of recurrence can be obtained by calculating for each year of follow up the number of patients who have required a second operation and expressing this number as a proportion of the number of patients followed up for that length of time. Thus, taking the time five years after the initial operation in the excision group, 83 patients have been followed and by this time 22 patients have required a second definitive operation giving a cumulative risk of recurrence of $26.5 \%$, whereas following the bypass operation 21 patients have been followed for five years and 12 have required a second operation, giving a cumulative risk of $57 \%$. The curves for the comparative cumulative risk of requiring a second major operation is shown in Figure 2.

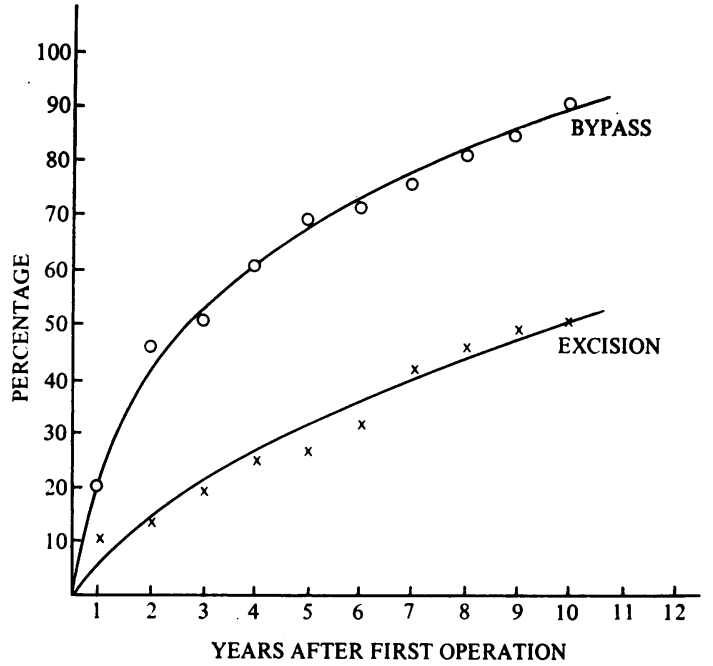

Fig. 2 The graph shows the cumulative risk of recurrence expressed as the chance of requiring a second definitive operation each year after the primary operation.

\section{INTERVAL BETWEEN FIRST AND SECOND} OPERATION

The interval between the first bypass and the next definitive operation was an average of 5.9 years, whereas in those patients primarily treated by excision the mean time interval between this operation and the next definitive operation was $4 \cdot 1$ years.

\section{INDICATIONS FOR SECOND OPERATION}

The principal indication for the second definitive operation was recorded in each patient and the comparative results are shown in the Table. It will be seen that most of the patients requiring a second definitive operation after primary excision needed it for recurrent Crohn's disease or symptoms of chronic intestinal obstruction as a result of fibrosis, whereas in those patients treated initially by bypass the commonest indications for a second definitive operation were local abscess or fistula which usually arose from the bypassed bowel.

\begin{tabular}{lcl}
\hline $\begin{array}{l}\text { Indication for Second } \\
\text { Definitive Operation }\end{array}$ & \multicolumn{2}{l}{ Primary Operation } \\
\cline { 2 - 3 } & $\begin{array}{l}\text { Excision } \\
(89 \text { patients })\end{array}$ & $\begin{array}{l}\text { Bypass } \\
(21 \text { patients })\end{array}$ \\
\hline Persistent fistula & $4(4.5 \%)$ & $7(33 \%)$ \\
Abscess & $5(5.5 \%)$ & $6(29 \%)$ \\
Stenosis or recurrent inflammation & $37(41.5 \%)$ & $5(24 \%)$ \\
Other reasons & - & $3(14 \%)$ \\
\hline
\end{tabular}

Table Results of excision and bypass compared 


\section{MORT ALITY}

There were no deaths following the primary operation.

\section{Discussion}

The conclusion that can be drawn from the results presented here suffer from the same limitations as those from all other series so far reported (Garlock et al, 1951; Atwell, Duthie, and Goligher, 1965; Schofield, 1965; Edwards, 1969) in that a comparison is made of two dissimilar groups operated on sequentially. For example, Garlock and his colleagues (1951) reported their experience from Mount Sinai Hospital where in the early part of this series they had operated on 45 patients by excision en bloc and side-to-side ileotransverse anastomosis. Six $(13.3 \%)$ had died and $20(23 \%)$ sustained a recurrence. They then abandoned the procedure in favour of the rather simpler operation of exclusion bypass, dividing the ileum proximal to the active disease, closing the distal end and anastomosing the proximal end to the side of the transverse colon. At the time of writing their paper they had operated on 57 patients by exclusion bypass with no deaths and only $13(22.8 \%)$ recurrences. They came to the obvious conclusion that bypass was the better operation. The bias in this argument is that the mortality was bound to improve from 1925 to 1950 . The lower mortality in the second half was due to improved anaesthesia and fluid and electrolyte replacement as much as it was to the superiority of the principle of bypass. The comparison of recurrence rates was also biased by the differing length of follow up, the exclusion bypass group having a shorter follow-up time in which recurrences could occur.

Although our series is retrospective, sequential, and not randomly selected, we are not concerned with comparing mortality, as there was none, but only the risk of recurrence. By calculating the cumulative risk of a second operation year by year the comparison of the two operations becomes valid and strongly favours the principle of excision. It should be noted, however, that the curves of the cumulative risk of recurrence show their major difference in the first five years and after this are roughly parallel.

When the indications for the re-operation are considered it appears that if the diseased segment is left in situ, as in the bypass operation, the risk of continued activity of the disease is great. Ulceration may progress through the wall of the bowel producing a local abscess or fistula. It could be argued that the risk of abscess and fistula would be less if the diseased segment were completely excluded from the stream of small bowel contents by dividing the ileum proximal to the inflamed segment as in the exclusion bypass operation popularized at Mount Sinai Hospital. However, Colcock (1964) warned that 'a closed loop of bowel always carries a risk of perforation', although he does not cite an example. We have seen one such complication (Steinberg, Cooke, and Williams, 1972) and another has been reported in an excluded loop by Waye and Lithgoe (1967). There is no convincing proof of the superiority of exclusion bypass over bypass in continuity.

In the patients who have had bypass the proportionately lower incidence of re-operation for stenosis or reactivation proximal to the anastomosis raises the question as to whether the wider anastomosis achieved in a bypass helps to protect against the subsequent development of stenosis that is so common in those patients who have a recurrence after excision. The question warrants future prospective study.

We believe that the evidence of the present study does not justify establishing a prospective randomized clinical trial to compare primary excision with primary bypass.

It must be emphasized that this study is specifically of patients operated on during their first presentation with Crohn's disease in the terminal ileum. Under these circumstances the disease is usually in an active phase with ulceration and oedema. It is possible that in these patients in particular bypass is contraindicated. In the patient with the relatively quiescent, 'burnt-out' disease with narrowing due to fibrosis and little mucosal ulceration, the operation of bypass may be of value.

\section{References}

Atwell, J. D., Duthie, H. L., and Goligher, J. C. (1965). The outcome of Crohn's disease. Brit. J. Surg., 52, 966-972.

Brooke, B. N. (1959). Granulomatous diseases of the intestine. Lancet, 2, 745-749.

Colcock, B. P. (1964). Regional enteritis: a surgical enigma. Surg. Clin. N. Amer., 44, 779-784.

Colcock, B. P., and Braasch, J. W. (1968). Inflammatory disease. In their Surgery of the Small Intestine in the Adult, pp. 89-115. Saunders, Philadelphia.

Edwards, H. (1969). Crohn's disease, an enquiry into its nature and consequences. Ann. roy. Coll. Surg. Engl., 44, 121-139.

Fielding, J. F., Cooke, W. T., and Williams, J. A. (1972). The incidence of recurrence in Crohn's disease. Surg. Gynec. Obstet., 134, 467-469.

Garlock, J. H., Crohn, B. B., Klein, S. H., and Yarnis, H. (1951). An appraisal of the long-term results of surgical treatment of regional ileitis. Gastroenterology, 19, 414-423.

Garlock, J. H. (1967). Surgery of the small intestine. In Garlock's Surgery of the Alimentary Tract. pp. 241-292. Butterworths, London.

Lennard-Jones, J. E., and Stalder, G. A. (1967). Prognosis after resection of chronic regional ileitis. Gut, 8, 332-336.

Schofield, P. F. (1965). The natural history and treatment of Crohn's disease. Ann. roy. Coll. Surg. Engl., 36, 258-279.

Steinberg, D. M., Cooke, W. T., and Alexander-Williams, J. (1972). Free perforation in Crohn's disease. In press.

Van Patter, W. N., Bargen, W. J., Dockerty, M. B., Feldman, W. H., Mayo, C. W., and Waugh, J. M. (1954). Regional enteritis. Gastroenterology, 26, 347-450.

Waye, J. D., and Lithgoe, C. (1967). Small bowel perforation in regional enteritis. Gastroenterology, 53, 625-629. 